Third Quarter, CY 1992

\author{
DISCIAAIMER
}

This report was prepared as an account of work sponsored by an agency of the United States Government. Neither the Ohio Power Company, the American, Electric Power Service Corporation, or the United States Government nor any. agency thereof, nor any of their employees, nor any of their contractors, subcontractors, or their employees makes any warranty, express or implied, or assumes any legal liability or responsibility for the accuracy, completeness, or usefulness of any information, apparatus, product, or process disclosed, or represents that its use would not infringe privately owned rights. Reference herein to any specific commercial product, process or service by tradename, trademark, manufacturer, or otherwise, does not necessarily constitute or imply its endorsement, recommerdation, or favoring by the ohio Power Company, the American Electric Power Service Corporation, and the United States Government or any agency thereof. The views and opinions of authors expressed herein do not necessarily state or reflect those of the ohio power company, the American Electric Power Service Corporation, and the United States Government or any agency thereof.

Prepared by:

American Electric Power Service Corporation Columbus, Ohio 43215

Prepared for:

The United States Department of Energy Under DOE Instrument NO. DE-FC21 $89 \mathrm{MC}-26042$

October, 1992 


\section{INTRODUCTION}

This is the twelfth technical progress report submitted to the Department of Energy (DOE) in connection with the cooperative Agreement between DOE and Ohio Power Company for the Tidd PFBC Hot Gas Clean Up Test Facility. This report covers the period of work completed during the Third Quarter of CY 1992.

The following are highlights of the activities that occurred during this report period:

- The primary activity during the Third Quarter was modification of the hot gas pipe spools and expansion joint assemblies.

- All pipe spools and expansion joint spools were clad with a Hastelloy $\mathrm{C2} 2$ liner for internal corrosion protection. This work was performed by Sterling Boiler \& Mechanical, Inc. of Evansville, Indiana. The work began on July 16 , and was completed on August 30,1992 .

- Following installation of the Hastelloy cladding, the pipe spools and expansion joint spools were internally insulated with a castable insulating refractory by Allen Refractories of Pataskala, Ohio. This activity began on August 13, and was completed on september 21,1992 .

PFBC HGCU Test Facility DOE Instrument No. DE-FC21 89MC26042 1
Technical Progress Report No. 5 Third Quarter
CY 1992 
Following installation of refractory, the pipe spools were returned to Tidd Plant. The expansion joint spools were returned to Badger Indistries of Zelienople, Pennsylvania, for reassembly with Hastelloy bellows. Reassembly of the expansion joints began on september 11, and should be completed during october, 1992 .

- Installation of the piping system at Tidd began on August 31 , and should be completed by october 23,1992 .

- During this quarter, 26 visits were made to vendor shops involved in rework of the HGCU piping to monitor progiess and check on the quality of work.

- A continuation application was submitted for the next budget period (No. 4), which will run from October 1, 1992 through August $31,1993$.

Project status as of september 30,1992 :

Installation of the piping system at Tidd was over $50 \%$ completed and projected to be finished by october 23, 1992. This includes time required to restore the combustor internals for HGCU operation and leak testing of the system. The system should be ready for start-up during the last week of october, 1992.

PFBC HGCU Test Facility DOE Instrument No. DE-FC21 89MC26042
Technical Progress Report No. 5 Third Quarter

CY 1992 
II. WORK ACCOMPLISHED DURING THE REPORTING PERIOD

\subsection{Detailed Design-Engineering}

In iddition to following the rework of the pipe spools and expansion joints, we completed the following tasks:

- Reviewed and modified the end connection design of each pipe spool and expansion joint to minimize gas flow behind the liners, erosion of refractory, and heat conduction to the outer pipe.

- Mechanical Design Department performed additional thermal and weight stress analyses to determine new nozzle loads and support :equirements.

- Issued purchase orders to Sterling Boiler, Allen Refractories, and Badger Industries for work described above.

- Issued purchase orders for miscellaneous other items such as gaskets, hangers, and instrument valves.

- Revised flow diagrams, system descriptions, and operating procedures to reflect operation of the system without the bypass cyclone connected to the system.

2.3 Westinghouse Engineering \& Design

See Appendix 1.

PFBC HGCU Test Facility

DOE Instrument No. DE-FC21 89MC26042
Technical Progress Report No. 5 Third Quarter

CY 1992 
3.2 Test Plan

One normal operating procedure was revised and routed for internal review during this quarter:

"HGCU Advanced Particle Filter system"

Work continued on the Detailed Test plan.

4.3 Westinghouse APF

The inlet, outlet, and manway nozzle flange faces (excluding the gasket surfaces) were coated with plasite 4300 for corrosion protection.

See Appendix 1 for other details.

4.4 APF 2

See Appendix 1.

4.5 Backup and Bypass Cyclones

After initial operation of the system in May, 1992, it was found upon inspection of the cyclones that heavy amounts of corrosive flue gas condensation formed in the backup cyclone which did not have flow through it, but was pressurized. Therefore, it was decided that the system would be configured to utilize only one cyclone at a time, one (the backup) for APF operation, and the other (bypass) for bypass operation. Blind flanges will be

PFBC HGCU Test Facility DOE Instrument No. DE-FC21 $89 \mathrm{MC} 26042$ Technical Progress Report No. 5
Third Quarter 
installed where appropriate to facilitate changing the system from one mode of operation to the other.

During this quarter, Plasite 4300 epoxy coating was applied to the manway nozzle inside surface and the flange faces on the inlet, outlet, and manway nozzles, as well as the ash collection vessel prewarming air discharge nozzle. The prewarming air discharge pipe connected to the ash collection vessel was replaced with Hastelloy material. Also, cracks in the cyclone refractory were repaired, as necessary.

\subsection{Ash Removal System}

\subsubsection{APF Ash Cooling}

The screw cooler closed cycle cooling water, lube oil, and hydraulic fluid systems were test operated and screw speed control checked. All systems performed satisfactorily. Additional pre-op testing is scheduled in October with the screw cooler pressurized to ensure satisfactory operation at pressurized conditions.

4.8.2 APF Ash Depressurization

Final pre-op testing and logic sequence check of the lockhopper system is scheduled for October prior to HGCU start-up.

PFBC HGCU Test Facility

DOE Instrument No. DE-FC21 89MC26042 5
Technical Progress Report No. 5 Third Quarter
CY 1992 


\subsection{Special Instrumentation}

Battelle representatives visited the site in september, 1992, to review accessibility for the ash sampling hardware. As a result, an additional platform will be added for this purpose.

PFBC HGCU Test Facility

DOE Instrument No. DE-FC21 89MC26042 6
Technical Progress Report No. 5 Third Quarter CY 1992 
As of September 30, 1992, the AEPSC Engineering, Design and Project Support cumulative work-hours were 56,976 , or 99.68 of the total 57,209 currently projected for the project. Figure 1 compares the actual workhours expended versus the current estimate. For the reporting period, a total of 3,236 hours were charged to the project by AEPSC personnel.

The actual DOE's cost expenditures during the Third Quarter - 1992 vere $\$ 1,756,301$. As of september 30,1992 , the cumulative DOE's cost expenditures were $\$ 13,134,841$. Figure 2 depicts the cumulative expenditure forecast for the project, which includes Westinghouse costshare. During the Third Quarter - 1992, Westinghouse was paid a total of $\$ 477,399$. Total payments to westinghouse through september 30,1992 were $\$ 5,051,076$. Major contractual commitments during this reporting period totaled $\$ 364,600$ and are summarized as follows:

$\frac{\text { Reference }}{\text { (Contract/Purchase order }}$
$28459-2$
$28506-2$
$06042-2$
$28458-2$

$\frac{\text { Description }}{\text { (Contractor) }}$

Modification of Expansion Joint Assemblies (Badger Industries)

Replacement Gaskets (ARGO Packing Co.)

Refractory lining in HGCU Piping (Allen Refractories)

Rework Piping (Sterling Boiler)

TOTAL
Contracted costs

$\$ 162,300$

33,800

77,500

91,000

$\$ 364,600$
PFBC HGCU Test Facility DOE Instrument No. DE-FC21 89MC26042 7
Technical Progress Report No. 5 Third Quarter
CY 1992 


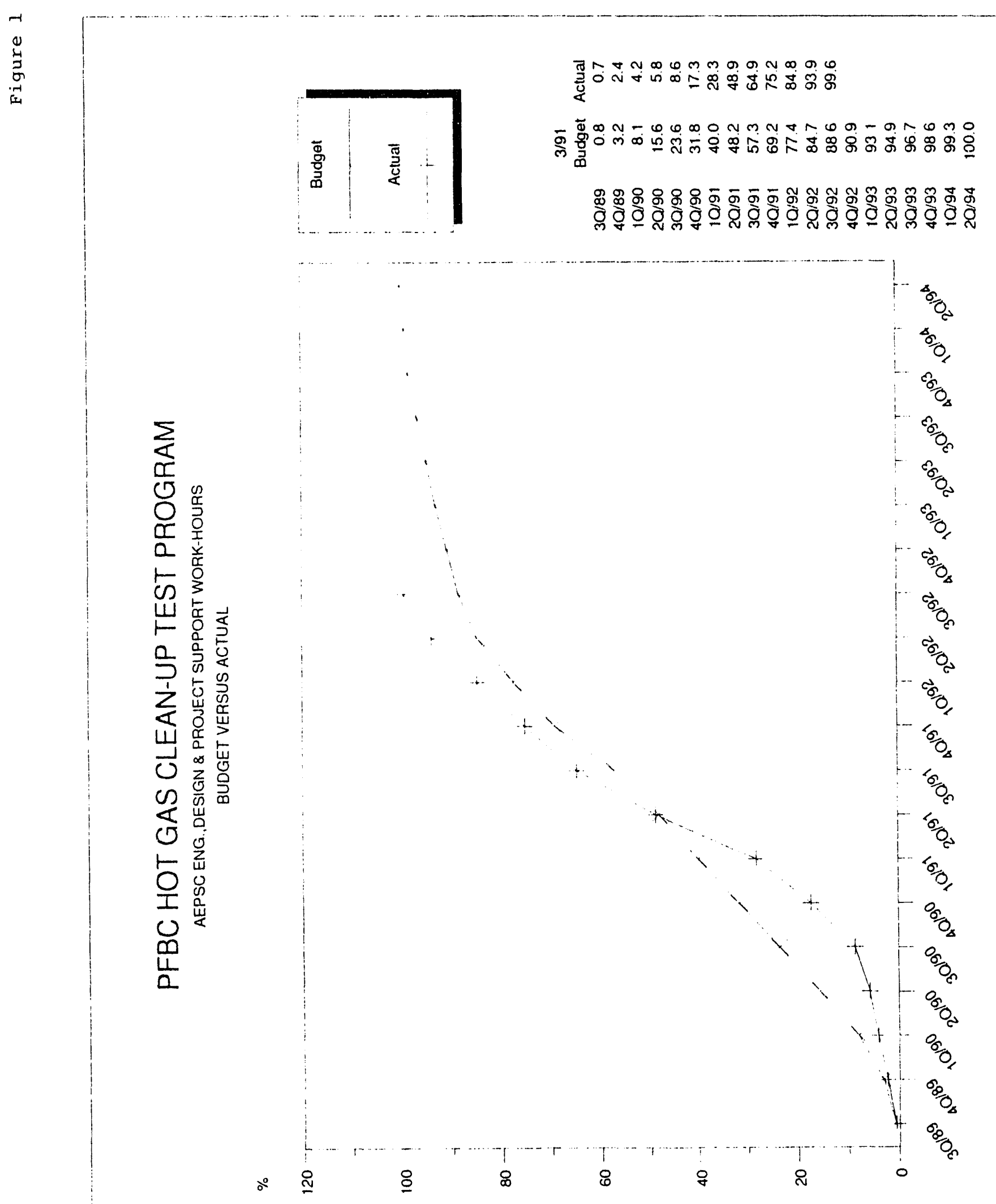




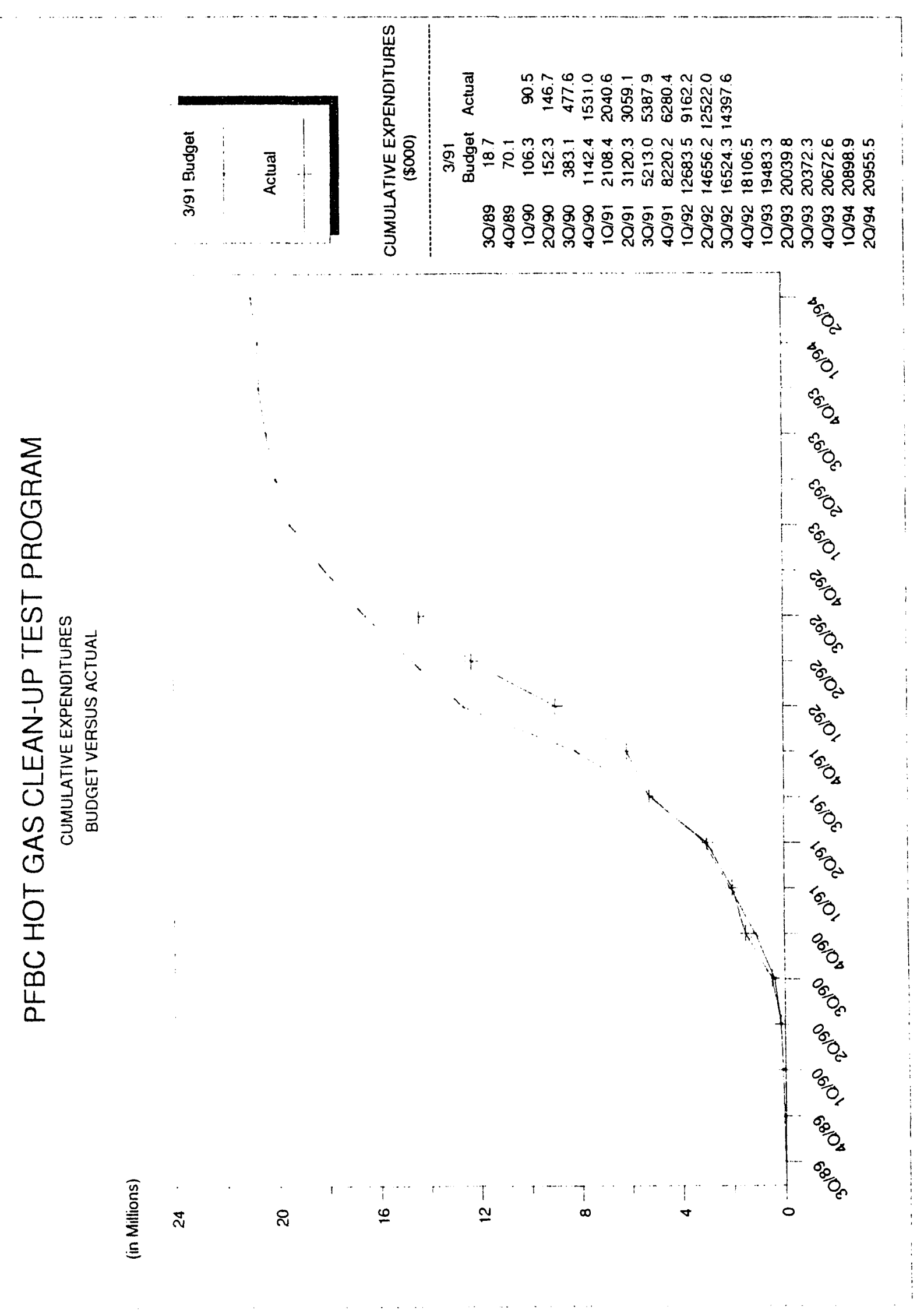




\section{ADVANCED PARTICLE FILTER}

Technical Progress Report No. 9

July through September 1992

Prepared by

Westinghouse Science and Technology Center

Pittsburgh, Pennsylvania

For

American Electric Power Service Corporation Columbus, Ohio

AEPSC Contract No. C8014 


\section{TIDD ADVANCED PARTICLE FILTER}

\section{GENERAL}

Startup activities continue to be delayed pending revision of hot gas piping by AEP. All milestones have been completed on or ahead of the required schedule with the exception of the acceptance test.

One pulse solenoid valve was reinstalled following factory repair of O-ring seals. A meeting was held in Columbus to discuss preop checkout, startup, and operation details. The failure mode response plans were also reviewed and revised to reflect elimination of the bypass cyclone and backup valve.

\section{TIDD APF SYSTEM DESIGN AND SUPPLY}

At this time all procurement is complete.

\section{SURVEILLANCE TEST PROGRAM}

A draft report describing the candle filter surveillance test program is attached in the Appendix.

Metal coupons have been installed in the head of the vessel at Tidd (see attached Figure). They include high alloy materials used in internals (i.e., RA333 and 310SS), as well as candidate materials for future fabrications (e.g., Inconel 617, Haynes 556, Haynes 188 and RA253MA. 


\section{KARHULA IDVANCED PARTICLE SYSTEM}

\section{GENERAL PROCUREMENT}

All hardware, including the hot seal plate, the cluster, the cluster support stand, the seal plate to tubesheet gaskets, the candle filters, the candle gaskets, the mounting hardware and surveillance material, has been shipped to and received at Ahlstrom.

Installation of all hardware was accomplished in September by joint efforts of Ahlstrom and Westinghouse. The tubesheet/seal plate/cluster assembly was leak tested and the vessel head was insulated in preparation for October startup.

\section{TESTING}

Thermal transient tests are ongoing to expose Conrs candle filters to rapid rates of cooling similar to those which may be encountered during a plant trip at Karhula. 

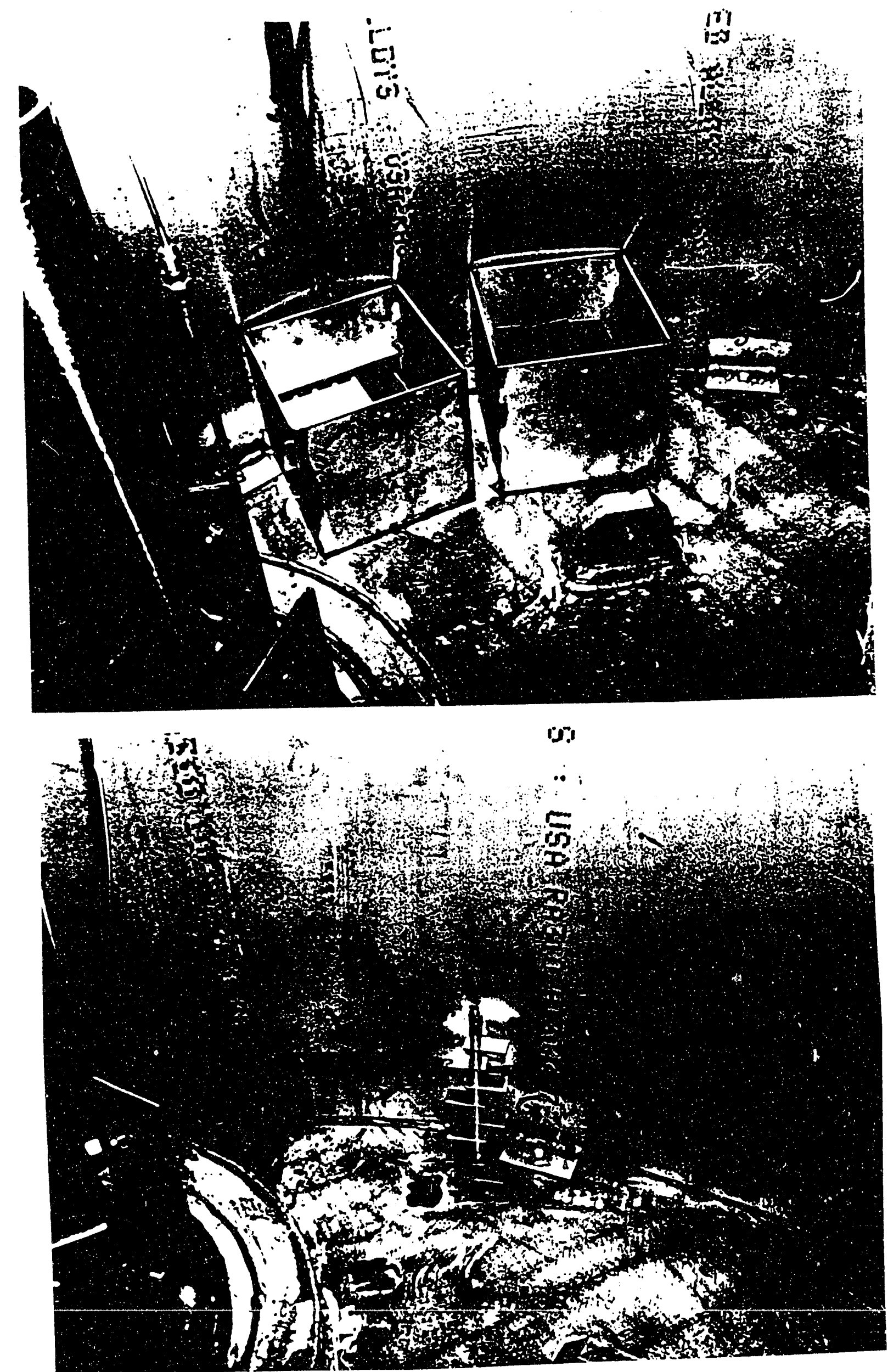

Figure 1 - Surveillance Test Coupons Positioned in APF Vessel Head 
APPENDIX 
Advanced Particle Candle Filter

Surveillance Program

At American Electric Power

M. A. Alvin

Gas Cleaning Systems

April 10, 1992 


\section{ABSTRACT}

Four hundred and fifty four clay bonded silicon carbide Schumacher Dia Schumalith candle filters were purchased for installation in the Westinghouse Advanced Particle Filtration (APF) system at the American Electric Power (AEP) plant in Brilliant, Ohio. A surveillance effort has been identified which will monitor candle filter performance and life during hot gas cleaning in AEP's pressurized fluidized-bed combustion system. A description of the candle surveillance program, strategy for candle filter location selection, as well as candle filter post-test characterization is provided in this memo. The period of effort for candle filter surveillance monitoring is planned through March 1994. 
1. Ceramic Candle Filter Surveillance Effort

A candle filter surveillance and characterization effort was initiated prior to assembly of the candle filter clusters in Westinghouse's Advanced Particle Filtration (APF) system at the American Electric Power plant in Brilliant, Ohio. A similar surveillance and characterization effort will be conducted throughout the course of hot gas filtration testing at this site. The purpose of the surveillance effort is to:

- Evaluate whether any physical and/or chemical changes occur within the clay bonded silicon carbide (SiC) Schumacher Dia Schumalith F40 candle filters during operation in pressurized fluidized-bed combustion (PFBC) systems.

- Evaluate whether: any physical and/or chemical changes occur within the ceranic matrix of any substitute candles used in the scheduled test program.

- Identify whether all candle filters experience similar process conditions throughout the entire filter vessel.

Initially forty-two 1.5 m Schumacher F40 candle filters were selected for use in the surveillance effort. All 42 candle filters were subjected to a nondestructive evaluation (NDE) using state-of-the-art time-of-flight (TOF) equipment (Appendix A) to verify and/or replicate the TOF values that were originally generated prior to shipment from the vendor site (Appendix B). These candles were clearly marked along the outside of each filter element's shipping box, as well as along each filter element body, for ease of identification and installation at the Tidd plant at preselected locations in the various filter clusters and plenums. Two of the original 42 surveillance candles were selected to 
remain at Westinghouse STC as controls, representing the clay bonded silicon carbide candle matrix in the original Schumacher F40 fabrication lot.

The 40 surveillance candle filter elements that were selected for use in this effort represent $\sim 10 \%$ of the 384 candles that were installed in all nine filter plenums. The $10 \%$ surveillance candle quantity was selected on the basis of paralleling a similar destructive characterization efiort that was performed by the vendor for qualification testing of the candle filter elements prior to shipment and delivery.

Qualification testing and initial Westinghouse inspection of each received candle filter included a visual inspection of the outer membrane coating, flange, and closed end cap section; and an assessment of perpendicularity and possible bowing. In addition, dimensional tolerance checks were conducted (i.e., length; outer and inner candle filter body diameters; flange diameter), individual candle filter weights were measured, TOF and $\triangle \mathrm{P}$ of $6 \pm 2$ mbar of air at $200 \mathrm{~m} / \mathrm{hr}$ (volume flow: $52 \mathrm{~m}^{3} / \mathrm{h}$ ) and particle collection efficiency were determined, and bubble tests mere performed (Appendix A). In the set of candles that was subjected to $10 \%$ destructive qualification testing, filters were randomly selected for burst pressure analysis (Appendix A); 0-ring room temperature strength testing; porosity; and determination of Young's modulus using grindosonic techniques (Appendix A). Note that the performance of all of the destructive and nondestructive analysis described above follows the format identified at the January 1991 DOE/METC candle filter workshop. 


\section{Criteria For Surveillance Candle Selection}

Forty-two 1.5 m Schumacher candle filters have been identified as surveillance candles in the cradle-to-grave effort at the American electric Power Tidd plant in Brilliant, Ohio. This is $\sim 10 \%$ of the 384 candle filters that were actually installed in the AEP APF vessel. The surveillance candles were selected on the basis of seven being chosen from the first and second fabrication lots; six from the third and fourth fabrication lots; and seven from the fifth and sixth fabrication lots (Table 1). The two control candles were selected from the first and sixth fabrication lots. This selection provides a sampling of all 450 as-fabricated candle filter elements that were initially purchased for use in this program. Each of the selected surveillance candles were intact, without any discoloration, bowing, chipping, etc., that may have been noted on alternate candle filters. 
TABLE 1

SURVEILLANCE CANDLE FILTERS

Shipment Location

Candle \#/Lot Candle Identification\# Crate\# Bow \# Column \#

\begin{tabular}{|c|c|c|c|c|c|}
\hline 1 & (1) & S/APF-2 & 1 & 2 & 4 \\
\hline 2 & (1) & S/APF-19 & 1 & 2 & 5 \\
\hline 3 & (1) & S/APF-28 & 1 & 3 & 8 \\
\hline 4 & (1) & S/APF-56 & 1 & 1 & 5 \\
\hline 5 & (1) & $\mathrm{S} / \mathrm{APF}-65$ & 1 & 1 & 4 \\
\hline 6 & (1) & S/APF-75 & 1 & 1 & 18 \\
\hline 7 & (1) & S/APF-83 & 1 & 2 & 8 \\
\hline 8 & (2) & S/APF-89 & 2 & 3 & 9 \\
\hline 9 & (2) & S/APF-87 & 2 & 3 & 2 \\
\hline 10 & (2) & S/APF-115 & 2 & 1 & 14 \\
\hline 11 & (2) & S/APF-129 & 2 & 1 & 2 \\
\hline 12 & (2) & $\mathrm{S} / \mathrm{APF}-150$ & 1 & 5 & 12 \\
\hline 13 & (2) & S/APF-164 & 1 & 5 & 2 \\
\hline 14 & (2) & S/APF-172 & 1 & 5 & 8 \\
\hline 15 & (3) & S/APF-176 & 3 & 1 & 7 \\
\hline 16 & (3) & S/APF-193 & 3 & 2 & 7 \\
\hline 17 & (3) & S/APF-213 & 2 & 4 & 7 \\
\hline 18 & (3) & S/APF-228 & 2 & 5 & 4 \\
\hline 19 & (3) & S/APF-238 & 2 & 5 & 14 \\
\hline 20 & (3) & S/APF-253 & 2 & 6 & 14 \\
\hline 21 & (4) & S/APF-263 & 4 & 2 & 6 \\
\hline 22 & (4) & S/APF-277 & 4 & 1 & 9 \\
\hline 23 & (4) & S/APF-297 & 3 & 3 & 10 \\
\hline 24 & (4) & S/APF - 314 & 3 & 4 & 13 \\
\hline 25 & (4) & S/APF-328 & 3 & 5 & 9 \\
\hline
\end{tabular}


TABLE 1 (cont'd)

SURVEILLANCE CANDLE FIITERS

Shipment Location

\begin{tabular}{|c|c|c|c|c|c|}
\hline \multirow[b]{2}{*}{ Candle } & \multirow[b]{2}{*}{ \#/Lot } & \multirow[b]{2}{*}{ Identification \# } & \multicolumn{3}{|c|}{ Shipment Location } \\
\hline & & & Crate \# & Row \# & Column \# \\
\hline 26 & $(4)$ & $\mathrm{S} / \mathrm{APF}-343$ & 3 & 6 & 13 \\
\hline 27 & (5) & $\mathrm{S} / \mathrm{APF}-355$ & 4 & 3 & 12 \\
\hline 28 & (5) & $\mathrm{S} / \mathrm{APF}-367$ & 4 & 4 & 12 \\
\hline 29 & (5) & S/APF-374 & 4 & 5 & 11 \\
\hline 30 & (5) & S/APF-393 & 4 & 6 & 15 \\
\hline 31 & (5) & S/APF-399 & 4 & 6 & 6 \\
\hline 32 & (5) & $\mathrm{S} / \mathrm{APF}-418$ & 5 & 1 & 8 \\
\hline 33 & (5) & $\mathrm{S} / \mathrm{APF}-436$ & 4 & 2 & 14 \\
\hline 34 & (6) & $\mathrm{S} / \mathrm{APF}-442$ & 5 & 4 & 1 \\
\hline 35 & (6) & $\mathrm{S} / \mathrm{APF}-458$ & 5 & 4 & 14 \\
\hline 36 & (6) & $\mathrm{S} / \mathrm{APF}-473$ & 5 & 5 & 13 \\
\hline 37 & (6) & S/APF-492 & 5 & 6 & 12 \\
\hline 38 & (6) & S/APF-504 & 5 & 2 & 7 \\
\hline 39 & (6) & $\mathrm{S} / \mathrm{APF}-521$ & 5 & 3 & 9 \\
\hline 40 & (6) & S/APF-528 & 5 & 3 & 14 \\
\hline
\end{tabular}

Control Candles

Shipment Location

Candle \#/Lot Candle Identification\# Crate\# Row \# Column \#

41

(1)

S/APF-6

1

2

11

$42 \quad(6)$

$\mathrm{S} / \mathrm{APF}-469$

5

5

11 


\section{Surveillance Candle Test Plan}

Westinghouse has taken the approach that two windows of opportunity will be available to recover surveillance candles from any location within the three cluster arrays. This will result when the filter vessel is opened, and all three candle cluster arrays are withdrawn from the filter vessel, tentatively at the end of hot gas filtration testing in 1992, and either in late 1993 or early 1994. During these periods of planned plant/filter system shutdown, between eight and fifteen surveillance candles will be removed for post-test NDE and destructive characterization (Section 5 ).

In the event of plant shutdown pending additional scheduled or alternate unscheduled maintenance between filter system startup and December 1992, and between January 1993 and March 1994, Westinghouse plans to remove between five and seven surveillance candle filters from the various cluster arrays. This will occur only if the filter vessel can be opened, and again the cluster arrays withdrawn from the vessel, since the designated surveillance candle positions are located along the top, middle, and bottom plenums and require ease of access for removal. If circumstances at that time bar cluster removal from the vessel, then all thirteen to fifteen surveillance candles will be removed at the end of testing in 1992 and 1994.

At alternate "preferred" intervals when the filter vessel remains sealed but inactive, the option exists to remove surveillance candles from the bottom plenums via entrance through the manway access into the lower section of the filter vessel body. Two candle filters are tentatively planned to be removed during each manway access.

At each time a surveillance candle filter is extracted from the various cluster arrays, either a new, fully characterized candle filter will be reinstalled into the original surveillance candle filter 
location, or the position will be blocked of to prevent further gas flow into the clean plenum chambers. The newly substituted candle filter will either be a similarly fabricated $1.5 \mathrm{~m}$ clay bonded silicon carbide Schumacher Dia Schumalith F40 filter, or an alternate candle such as a 1.5 m alumina/mullite Coors Ceramic candle filter. At the discretion of AEP and DOE, Westinghouse will only instail the Coors candles after they have undergone extensive qualification testing, and when Westinghouse has full knowledge of the viability of the Coors ca: dle filters to withstand PFBC conditions as demonstrated through planned high temperature, high pressure testing. 


\section{Surveillance Candle Filter Positions}

The surveillance candle filters have been positioned at various locations in the Westinghouse APF system (Figure 1) so that candles can be removed and subsequently evaluated to demonstrate the

- Effect that filter operating time has on the physical/chemical properties of the clay bonded silicon carbide Schumacher Dia Schumalith F40 matrix,

- Effect that vertical (cluster) and lateral (plenum) position may have on filter stability, performance, and operational life.

Westinghouse has selected a series of identical candle filter locations for the tentatively planned 1992 and 1994 plant/filter system shutdown. Since these candles are located throughout the various cluster arrays, easy access is required, and therefore the filter clusters must be withdrawn from the vessel to achieve successful removal of the surveillance candles.

Similarly in the event of plant shutdown pending scheduled or alternate maintenance within both the 1992 and 1993-1994 interim testing periods, a series of surveillance candles which are again located at identical positions can be removed during each interim shutdown period. Removal of these filters will also require easy access, since they are positioned throughout the various cluster arrays. In the event that the interim shutdown periods do not occur, then, this series of candles can be removed during the planned plant/filter system shutdown in 1992 and 1994. 


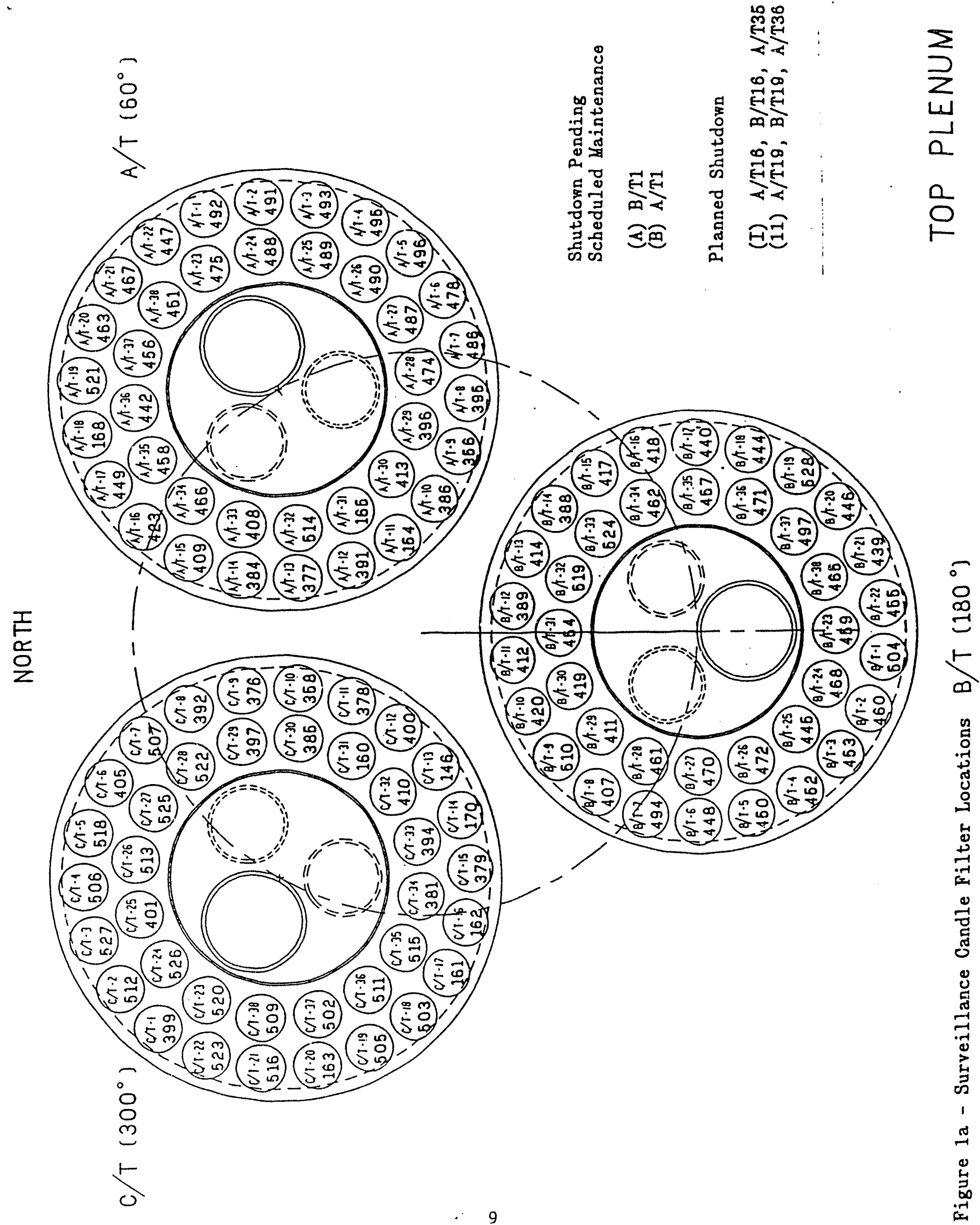




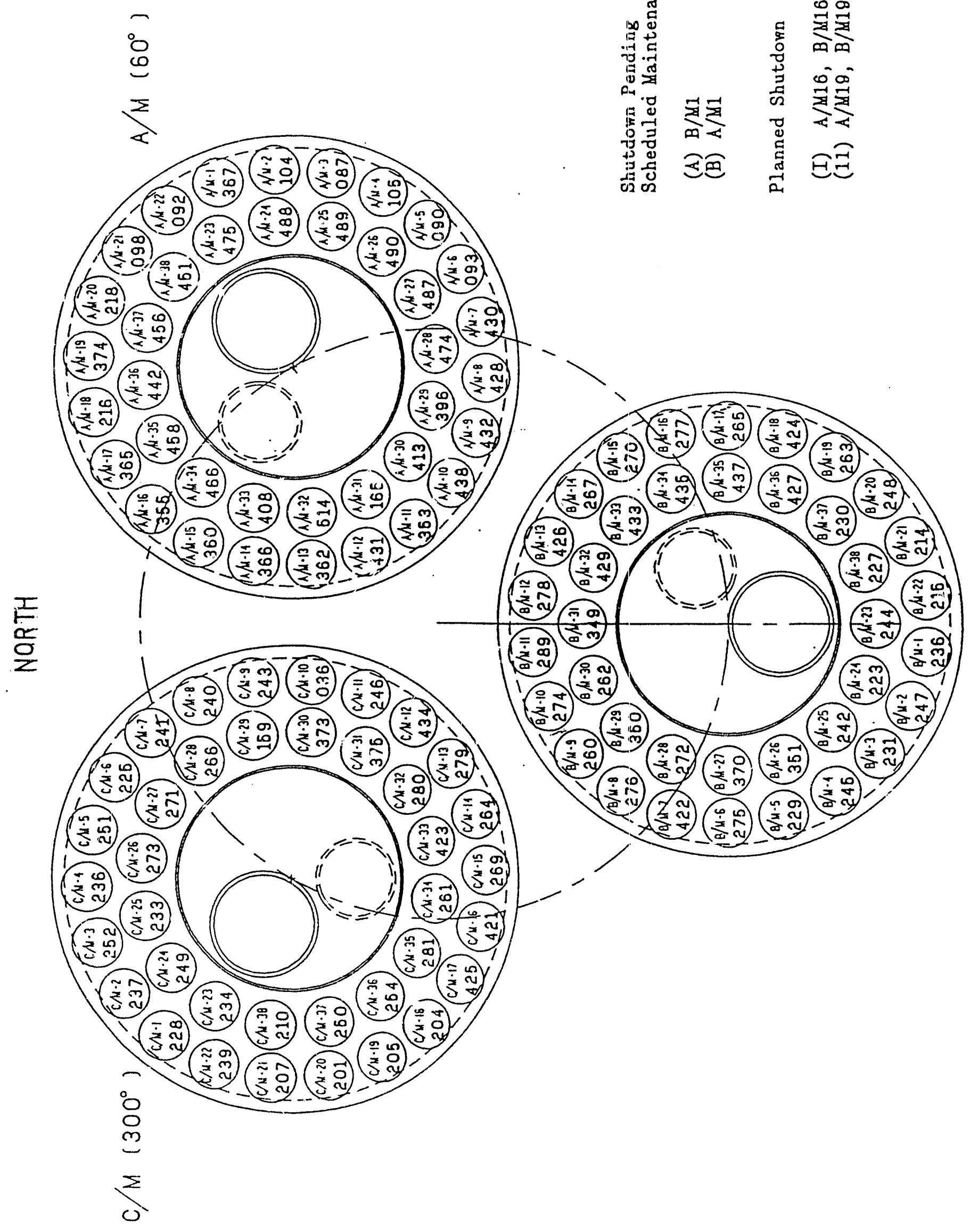




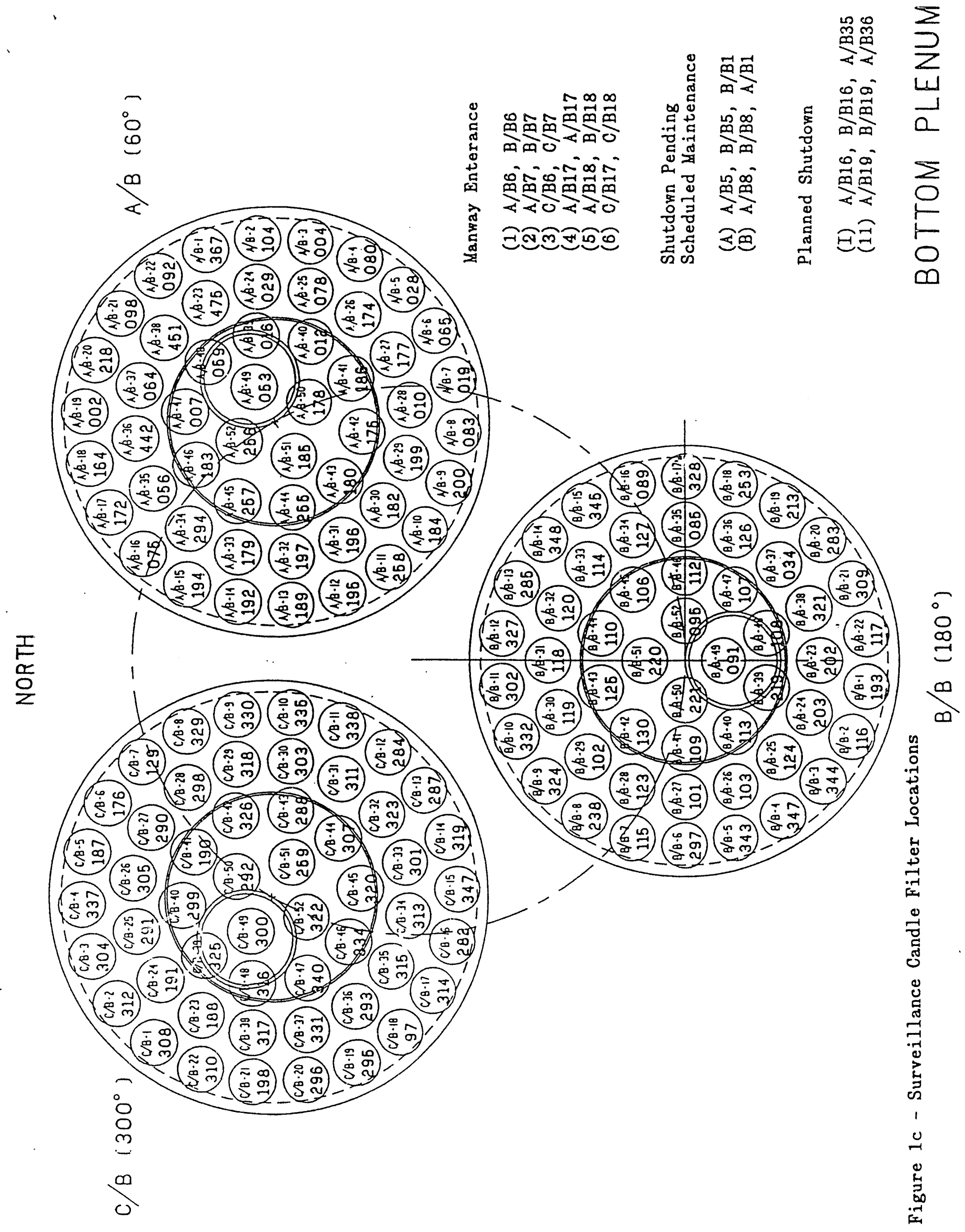


In the event that access to the filter can be achieved via entrance through the filter vessel manway, candles will be removed only along the bottom plenum of each cluster. Identical candle positions have been identified for this exercise on each plenum such that at various time intervals, a time exposure profile will be generated from the NDE and destructive characterizations which are described in Section 5. If all bottom plenum surveillance candles are not removed during the manway access periods, these candles will either remain in place, or selectively will be extracted at a later designated time. 


\section{Post-Test Candle Filier Characterization}

Once a surveillance candle filter has been removed from the Westinghouse APF system it will be subjected to a similar series of NDE and destructive evaluations as were performed prior to installation. Initially the candles will undergo a visual inspection to determine whether bowing has occurred during APF testing. Prior to removal of the ash cake which has formed along the filter surface, a room temperature permeability test will be performed. Each candle will then be cleaned with care being taken so as not to mar or destroy the outer membrane coating. Fines that are removed will be retained for further analyses. The cleaned candle filters will then be resubjected to room temperature gas permeability measurements. The latter will be used to reflect the effect of ash conditioning along the filter surface as a result of PFBC process exposure at Tidd.

Each candle will then be weighed, and will undergo a dimensional evaluation which will include measurement of the candle filter length, outer and inner body diameter, flange diameter, and determination of perpendicularity. A borescope inspection will be performed along the entire ID length of the candle filter body. A visual inspection will be performed to identify the nature of the outer membrane coating, and whether cracks or changes are evident along the flange and closed bottom section of the candle. The candle will then be subjected to a full length TOF. Select candles will undergo additional TOF measurements in the radial direction along the coarse-to-fine grain transition section, as well as TOF measurements using tandem transducers in the axial direction over the entire circumference along the transition zone. Each candle filter will be subjected to bubble testing to identify whether cracks are evident. 
The candle filters will then be subjected to a series of destructive characterization tests. These will involve sectioning the candle so as to provide material for room temperature and hot strength C-ring compression and possibly tension testing; burst strength analysis; and a grindosonic evaluation to reestablish Young's modulus. Samples of material will undergo further characterization via $x$-ray diffraction (XRD) analysis to determine whether phase changes have occurred within the filter matrix. Sections of the exposed candle filters will be subjected to scanning electron microscopy/energy dispersive $x$-ray analysis (SEM/EDAX) to identify whether changes have occurred within either the outer membrane coating, or within the coarse grained silicon carbide matrix. Similarly SEM will attempt to be used to identify the nature of fines adherence along the candle filter surface. SEM/EDAX and elemental microprobe (EMA) will be used to determine whether and/or to what extent fines have penetrated into the coarse grain structure of the candle matrix.

In the event that a candle failure results during test operation in the Hestinghouse hot gas filtration system, the failed candle filter will be subjected to the above series of tests after a fracture analysis has been performed along the failed section of the filter. If candle changeout is required, substituted candles will undergo a similar preinstallation inspection and NDE characterization as previously described. 


\section{Material Assessment Summary}

Information that will be generated in the post-test evaluation of the surveillance candles will be used to identify the effect of surface conditioning as a function of candle operating time under PFBC conditions (Schematically illustrated in Figure 2). Similarly bubble test analysis, TOF, grindosonic evaluation, hot C-ring strength testing, and room temperature burst testing information will be generated which will identify whether physical changes have occurred within the ceramic filter matrix as a function of candle operating time. The influence that PFBC gas chemistry and particulate fines have on the stability of the clay bonded silicon carbide matrix will be determined through the use of XRD and SEM/EDAX analyses.

Information that will be generated throughout the surveillance effort will be integrated with previous pilot and bench-scale information that has already been reported in the literature. Finally, the information generated in the surveillance test effort will be used to provide an understanding of clay bonded silicon carbide filter material life and candle performance under commercial-scale PFBC process conditions. 


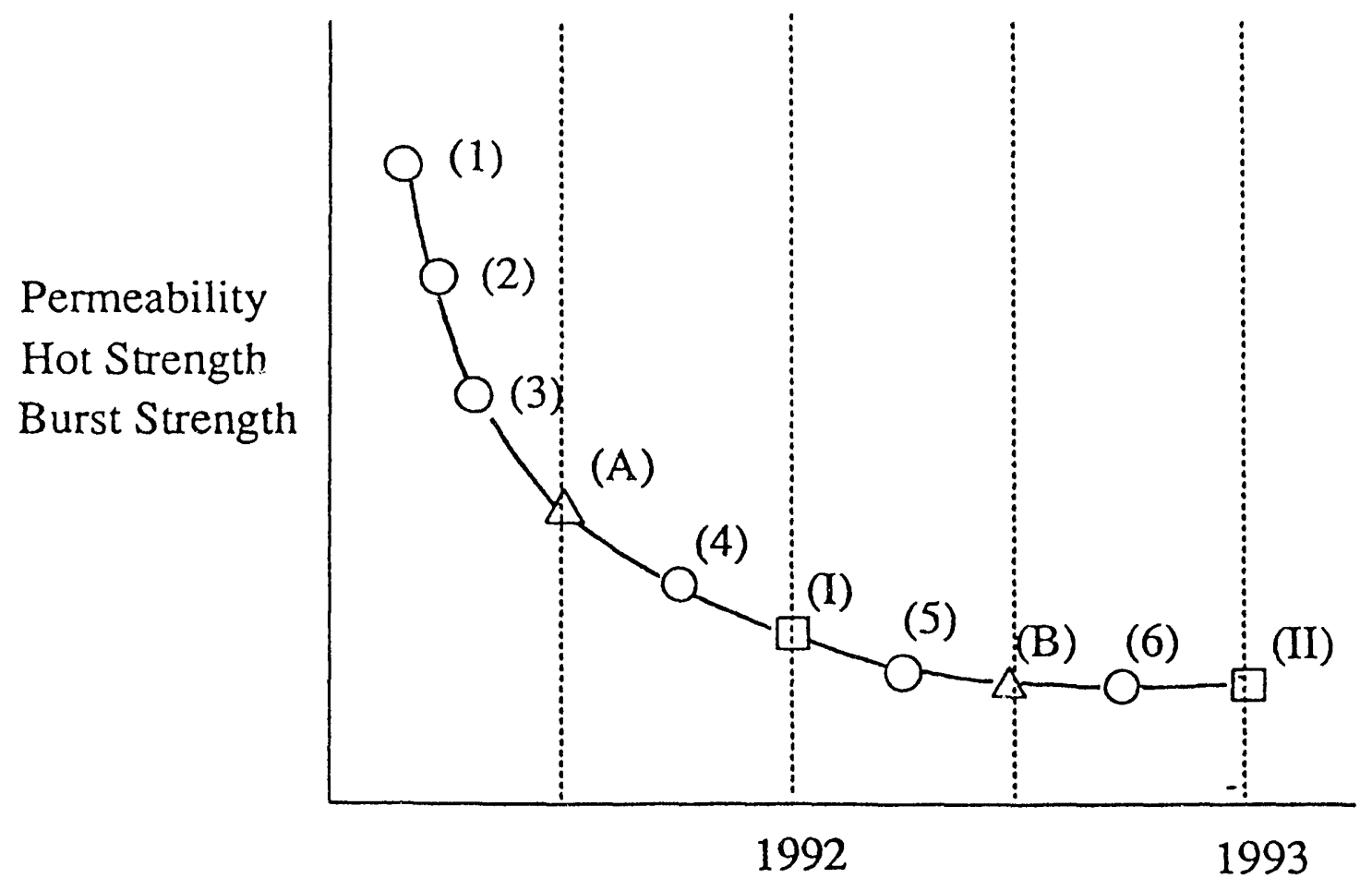

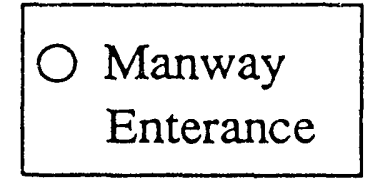

(1) $\mathrm{A} / \mathrm{B} 6, \mathrm{~B} / \mathrm{B} 6$

(2) $A / B 7, B / B 7$

(3) $\mathrm{C} / \mathrm{B} 6, \mathrm{C} / \mathrm{B} 7$

(4) $\mathrm{A} / \mathrm{B} 17, \mathrm{~B} / \mathrm{B} 17$

(5) $\mathrm{A} / \mathrm{B} 18, \mathrm{~B} / \mathrm{B} 18$

(6) $\mathrm{C} / \mathrm{B} 17, \mathrm{C} / \mathrm{B} 18$

\section{$\triangle$ Shutdown Pending Scheduled Maintenance}

(A) A/B5, B/B5, B/T1 $\mathrm{B} / \mathrm{M} 1, \mathrm{~B} / \mathrm{B} 1$

(B) A/B8, B/B8, A/T1, $\mathrm{A} / \mathrm{M} 1, \mathrm{~A} / \mathrm{B} 1$
Planned Shutdown

(I) $\mathrm{A} / \mathrm{B} 16, \mathrm{~B} / \mathrm{B} 16$ A/M16, B/M16 A/T16, B/T16 A/T35, A/B35

(II) $\mathrm{A} / \mathrm{B} 19, \mathrm{~B} / \mathrm{B} 19$ A/M19, B/M19 A/T19, B/T19 A/T36, A/B36

Figure 2 - Post-Test Surveillance Candle Properties 


\section{ACKNOWLEDGMENTS}

A special acknowledgement is extended to Dr. Mustan Attaar and Mr. Fran Gradich for their efforts in performing the initial time-offlight measurements on the surveillance candle filters. 
APPENDIX A

SELECT NDE AND DESTRUCTTVE ANALYSIS TECHNIQUES USED IN SURVEILLANCE CANDLE FILTER CHARACTERIZATION 
APPENDIX A

\author{
SELECT NDE AND DESTRUCTTVE ANALYSIS TECHNIQUES \\ USED IN SURVETLLANCE CANDLE FILTER CHARACTERIZATION
}

The following discussion is provided to further clarify the use of time-of-flight (TOF), grindosonic, bubble point, and burst pressure testing of forty as-fabricated and field tested candle filters in the Candle Surveillance Task of Westinghouse-AEP hot gas filtration demonstration program. These techniques will be used in addition to an initial, nondestructive (NDE), visual inspection of the outer membrane, flange, and closed end cap section, borescope inspection of the ID surface, and assessment of candle perpendicularity and/or bowing. Further in-depth, destructive, material characterization will be performed to assist in the identification of changes that may have occurred with the clay bonded silicon carbide candle filter matrix after high temperature filtration at Tidd. These will include room temperature strength and hot strength characterization of the field tested candles (i.e., C-ring compression and tension testing); $x$-ray diffraction analysis (XRD) to identify changes within the binder, grain boundary, grain or fiber mat structure; scanning electron microscopy analysis (SEM) to detail changes within the morphology of the candle filter matrix, and energy dispersive $x$-ray analysis (EDA) to qualitatively estimate the composition of the matrix after exposure to the high temperature gas filtration environment.

\title{
Time-0f-Flight Testing
}

Time-of-flight characterization is a nondestructive evaluation technique which will be performed on all forty (40) surveillance candles prior to installation at Tidd. Time-of-flight characterization will 
also be performed on each of the designated forty candle filter elements after exposure to the high temperature gas filtration environment in the 384 candle filter cluster array. With time-of-flight, an ultrasonic pulse is sent through the candle filter (i.e., from end-to-end, or along specified segments of the candle as at the dense-to-coarse transition section). The velocity at which the ultrasonic pulse travels depends on the density and the elastic properties of the as-fabricated or field tested clay bonded silicon carbide matrix. These properties correlate with material strength.

With time-of-flight, candle filters are individually contacted with a receiver at one end, and an ultrasonic transmitting source at the other. The velocity of the ultrasonic pulse $(v)$ is calculated from the relationship of the path length $(1)$ to transit time $(t)$ as follows:

$$
\mathbf{v}=1 / \mathrm{t} \text {. }
$$

From the ultrasonic velocity, Young's modulus is determined. By comparing the ultrasonic velocity of the candle filter elements initially (i.e., as-fabricated and supplied by the vendor) with the ultrasonic velocity after high temperature filtration at $T$ idd, we can determine whether and to what extent Young's modulus and the strength of the clay bonded silicon carbide matrix have changed. Typically the strength of the ceramic candle filter matrix is known to be reduced during use at high temperature. With the as-fabricated and field tested time-of-flight information, and estimates on the stresses induced within the candle filter (i.e., geometry, thermal, etc.), we can estimate candle filter material life for use at process conditions.

\section{Grindosonic Testing}

Grindosonic testing is alternate nondestructive evaluation technique which will be performed on all forty surveillance candles prior to installation. Similar to time-of-flight, grindosonic 
characterization will also be performed on each of the forty designated candle filter elements after exposure to the high temperature gas filtration environment in the 384 candle filter cluster array. The grindosonic characterization utilizes resonance frequency measurements to determine the elastic properties of each candle filter element.

\section{Grindosonic testing is typically performed by inducing} vibrations within the candle filter through a light short "strike" or "knock" to the candle filter surface. After a short damping period, the candle oscillates with a specific resonance frequency (eigenfrequency). A piezoelectric sensor is used to measure the vibration and transmit signals to a Grindosonic device for processing. The resonance frequency or vibration is periodic, and proportional to the grindosonic "R" value. Young's modulus is then calculated as shown by the following formula:

$$
E=(m \cdot F) / R^{2}
$$

where $m=$ weight $F=$ form factor; and $R=$ Grindosonic value.

The determined Young's modulus of the ceramic candle filters correlates with their strength. By identifying the grindosonic Young's modulus of the as-fabricated candles prior to installation at Tidd, as well as after high temperature filtration, we can determine whether changes have occurred within the material properties of the clay bonded silicon carbide candle matrix.

\section{Bubble Point Testing}

Bubble point testing is an additional, nondestructive, visual inspection technique which will be completed after an initial visual inspection of exch of the specified forty, field tested candle filter elements (i.e., dimensional checks, perpendicularity, concentricity, straightness, adherence of dust, appearance of the continuous surface 
coating, absence of cracks, chips, nicks, etc.) has been conducted. Since the vendor has subjected each candle filter to an initial bubble point test, we will only bubble point characterize candles that have been exposed at Tidd.

Bubble point testing is based on the LaPlace equation which shows the relationship between the measured pressure difference $(\Delta p)$ and the diameter (D) of a cylindrical pore within the material. In the following equation, $\sigma$ is the surface tension of the liquid used, and I is the wetting angle:

$$
\Delta \mathrm{p}=(4 \sigma / D) \cdot \cos \Upsilon
$$

In order to conduct a bubble point test, a candle filter element is placed in a tank that is filled with water. Pressurized air is passed through tubing and a stopper that are inserted into the flange ID. As air pressure is increased inside the candle, bubble patterns are forced to form on the outside wetted candle filter surface. The first bubble to appear gives an indication of the maximum pore size. If after exposure at Tidd the bubble pore size changes dramatically from the original, as-fabricated bubble pore size, then changes within the binder phase or silicon carbide grain dimensions are suspected. Porosity changes within the clay bonded silicon carbide matrix are directly related to the room temperature or "cold" strength of the filter material. In addition, bubble patterns identify whether cracks or holes are present along the membrane or outer surface coating of the filter element. Furthermore, with increasing air mass flow, inhomogeneities in the coarse structural or dense flange section can be detected by the non-uniform air bubble surface patterns. 


\section{Burst Pressure Testing}

After the candle filters have been exposed at Tidd and all visual inspection and nondestructive testing have been completed, two $250 \mathrm{~mm}$ long sections will be removed from the top flange area and midbody of each candle filter. Each $250 \mathrm{~mm}$ long section will individually be slipped onto a water-filled rubber bladder. Pressure in the waterfilled bladder will be increased until the candle section breaks. The force which acts from inside-out (tensile stress), gives an indication of the minimum stress level that the exposed candle filters could withstand.

Typically the original, as-fabricated burst strength of the candle filters used at Tidd have a burst pressure strength of 60 bar as measured by the vendor. If changes within the ceramic matrix orcur during high temperature filtration, causing either crack formations or an overall loss in strength, a decrease in the burst pressure test values would be expected. Note that two sections of the candle will be burst tested. By testing the flange area, we can determine whether filter mounting or cold pulse cleaning dramatically changes the ceramic matrix. Similarily, by testing a mid-body section, we will be able to determine whether the "cooler" pulse changes the ceramic matrix properties. By comparing the flange and mid-body burst test values we can estimate whether the candle matrix properties have changed uniformly during hot gas filtration.

Note that currently a direct correlation is believed to exist between the burst pressure and time-of flight values (i.e., as burst strength increases, time-of-flight values decrease). If the candle matrix undergoes a reduction in strength (burst or C-ring) during longterm exposure at Tidd, we will be able to directly correlate and verify changes obtained from our time-of-flight testing. Also note that C-ring compression or tension testing reflects localized material strength 
(i.e., C-rings are typically $15 \mathrm{~mm}$ wide), while burst pressure reflects the strength of the material over a larger area $(250 \mathrm{~mm})$. Burst pressure is therefore expected to characterize a more representative "flaw" population within the material, and generate an "overall" estimate of material strengin. Once again an extensive burst pressure databas has not been established for either as-fabricated or field tested candle filters. Similarly, correlations of the burst pressure, time-of-flight, and room temperature and hot strength values need to be further developed and confirmed.

\section{Summary}

Both time-of-flight and grindosonics measurements are nondestructive techniques which can be used relatively quickly to determine Young's modulus and to calculate the strength of the candle filter matrix. Currently a time-of-flight or grindosonics database has not been extensively developed, particularly for candle filters after field exposure. By generating the time-of-flight and grindosonics information, further evidence is provided which will support the more traditional, but labor intensive destructive C-ring strength characterization.

Since the room temperature ancl process temperature candle filter strengths are known to differ (i.e., lower strength at process temperature conditions as a result of "softening" of the binder phase at high temperature), destructive C-ring strength testing will be performed at both temperatures in the candle filter element surveillance task. By generating the time-of-flight, grindosonics, room temperature strength, and hot strength, we can begin to develop relationships between both nondestructive and destructive evaluation techniques. These relationships will provide the basis for projecting overall material operating life for the current candle filter elements, as well as direction for processing and manufacture of filters with extended operating life. 
APPENDIX B

SURVEILLANCE CANDLE TIME-OF-FLIGHT DATA

B-1 
APPENDIX B

SURVEILLANCE CANDLE TTME-OF-FLIGHT DATA

Nondestructive evaluation (NDE) techniques were used to characterize the forty-two surveillance candle filters that were placed in the Westinghouse Advanced Particle Filtration system at the American Electric Power plant facility in Brilliant, Ohio. Time-of-flight (TOF) data were generated using an UItran BR-640A broad band receiver and a BR-9400A burst pulser (Figure B-1). Each candle was supported on two Vblocks which rested on a roller bearing plate that permitted free lateral movement during pressure contact with the transmitting and receiving transducers.

Dry couplant urethane membranes (Figure B-2) were placed on the surface of both transmitting and receiving $50 \mathrm{Khz}$ Panametrics $\mathrm{X}-1021$ transducers. The suspended transmitting transducer was pushed against the bottom closed end section of the candle filter via a spherical support to ensure flat contact with the candle surface. The receiving transducer was mounted in a spring loaded holder for contact with the candle flange. Spring deflection at contact was adjusted to transmit $10.04 \mathrm{lb}$ force $(45 \mathrm{~N})$. The equipment was periodically calibrated using a two-step Plexiglas standard which consisted of a $4 \times 4 \times 4$ inch cube with a $2 \times 4 \times 6$ inch extension. TOF values through the urethane membrane and Plexiglas standard are presented in Table B-1. A $2 \mu \mathrm{s}$ correction factor was identified for zero time transmission.

The Ultran equipment that was used for this effort was connected to an oscilloscope, as well as a Sonix digital acquisition system. TOF data that were generated for each surveillance candle filter were 
digitally logged and stored in a computer file. For select candle filters, FFT (Fast Fourier Transformation) waveforms were also generated and stored for possible further analyses.

Each TOF measurement was obtained using a $6.25 \mathrm{Mhz}$ digitizing rate where a threshold of one was used for data obtained between 280 and $362.24 \mu \mathrm{s}$. The collection accuracy of the equipment was established at $\pm 0.7 \mu \mathrm{s}$. The resulting TOF data generated for the forty-two surveillance candles are presented in Table B-2. Thirty-seven of the 42 candle filters are identified to be within $5 \mu \mathrm{s}$ of the TOF data that were generated by Schumacher. The remaining five candle filters have TOF values that exceed Schumacher's data by 14 to $29 \mu \mathrm{s}$. Each of the 5 candles exceed the maximum TOF tolerance ( $345 \mu \mathrm{s}$ ) that was specified by Westinghouse for candle filter qualification and acceptance. The TOF variation identified in Table B-2 is considered to be significant, since Schumacher does not expect to have a TOF variation $>10 \mu \mathrm{s}$ in the entire production batch of candle filters.

The TOF data presented in Table B-2 are pressure sensitive in most cases. For several of the candle filters with high TOF values, application of a force that was greater than the spring load pressure would bring the TOF value to within $2 \mu \mathrm{s}$ of Schumacher's data. This was considered to be principally due to the seating the urethane membrane on the relatively rough candle filter surface. Conversely, no significant change in the TOF value could be detected in several candles when additional pressure was applied. We suspect that material properties (i.e., density, porosity, strength, possible flaws, etc.) are influencing the resulting high TOF data.

In an attempt to determine whether flaws are present within the 1.5 m candles, through-thickness transmission measurements were conducted along the fine-to-coarse grain transition section of six surveillance candle filters. This area was selected for through- 
thickness analysis since failure has frequently been detected in this segment of the candle filter. The results of the through-thickness effort are summarized in Appendix C. 
TABLE B-1

\title{
PLEXIGLAS CALIBRATION SENSITIVITY
}

\author{
Contact (with membranes touching \\ $2^{n}$ Plexiglas \\ 4" Plexiglas \\ 6" Plexiglas
}

$1.92 \mu \mathrm{s}$

$21.12 \mu \mathrm{s}$

$40.16 \mu \mathrm{s}$

$59.04 \mu \mathrm{s}$ 
COMPARISON OF TIME-OF-FLIGHT DATA

\begin{tabular}{|c|c|c|c|c|c|}
\hline Candle & $\begin{array}{c}\text { Candle } \\
\text { Identification \# }\end{array}$ & $\begin{array}{l}\text { Schumacher } \\
\text { TOF, } \mu_{\text {a }}\end{array}$ & $\begin{array}{l}\text { (W) } \\
\text { Raw } \\
\text { Data } \\
\end{array}$ & 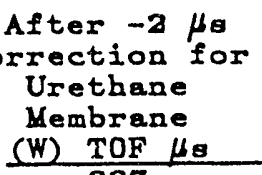 & $\begin{array}{c}\text { Difference } \\
\text { (W)-Schumecher }\end{array}$ \\
\hline 1 & S/APF-3 & 338 & 339 & 337 & -2 \\
\hline 2 & S/APF-18 & 340 & 340 & 338 & -2 \\
\hline 3 & S/APF-28 & 341 & $\mathbf{3 4 3}$ & 341 & 0 \\
\hline 4 & S/APF -56 & 344 & 348 & 344 & 0 \\
\hline 5 & S/APF-6E & 345 & 348 & 346 & 1 \\
\hline 6 & S/APF-75 & $\mathbf{3 4 3}$ & $\mathbf{3 4 3}$ & 341 & -2 \\
\hline 7 & S/APF-83 & $\mathbf{3 3 4}$ & 338 & 337 & 3 \\
\hline 8 & $\mathrm{~S} / \mathrm{APF}-89$ & 334 & 350 & $\mathbf{3 4 8}$ & 14 \\
\hline$\theta$ & S/APF - Q7 & 331 & $351 *$ & 348 & 18 \\
\hline 10 & S/APF-115 & 333 & 335 & 333 & 0 \\
\hline 11 & S/APF-128 & $\mathbf{3 4 3}$ & $347 *$ & 345 & 2 \\
\hline 12 & S/APF-150 & 340 & 360 & 358 & 18 \\
\hline 13 & S/APF-164 & 338 & 338 & 338 & -2 \\
\hline 14 & S/APF-172 & 345 & $\mathbf{3 4 2}$ & $\mathbf{3 4 0}$ & -5 \\
\hline 15 & S/APF-176 & 334 & 333 & 331 & -3 \\
\hline 16 & S/APF-193 & 325 & 323+ & 321 & -4 \\
\hline 17 & S/APF-213 & 323 & 323 & 321 & -2 \\
\hline 18 & S/APF-228 & 338 & 336 & $\mathbf{3 3 4}$ & -5 \\
\hline 18 & S/APF-238 & 332 & 331 & 328 & -3 \\
\hline 20 & S/APF-253 & 336 & 335 & 333 & -3 \\
\hline 21 & S/APF-263 & $\mathbf{3 3 7}$ & 338 & 334 & -3 \\
\hline $\mathbf{2 3}$ & S/APF-277 & 330 & 361 & 358 & 28 \\
\hline 23 & S/APF - 287 & 331 & 334 & 332 & 1 \\
\hline 24 & S/APF-314 & 328 & 332 & 330 & 1 \\
\hline 25 & S/APF-328 & $\mathbf{3 3 4}$ & 338 & $\mathbf{3 3 7}$ & 3 \\
\hline 28 & $S / A P F-343$ & $\mathbf{3 4 4}$ & $345 *$ & 343 & -1 \\
\hline 27 & S/APF-355 & 338 & 338 & 336 & -2 \\
\hline 28 & S/APF-367 & 330 & 332 & 330 & 0 \\
\hline 28 & S/APF-374 & 343 & $345 *$ & 343 & 0 \\
\hline 30 & S/APF-383 & 337 & 339 & $\mathbf{3 3 7}$ & 0 \\
\hline 31 & S/APF-389 & $\mathbf{3 3 4}$ & $\mathbf{3 3 7}$ & 335 & 1 \\
\hline 32 & $S / A P F-418$ & $\mathbf{3 2 7}$ & $348 *+$ & 346 & 19 \\
\hline $\mathbf{3 3}$ & S/APF -436 & 333 & 338 & $\mathbf{3 3 4}$ & 1 \\
\hline 34 & $S / A P F-442$ & 328 & 331 & 328 & 1 \\
\hline 35 & $\mathrm{~S} / \mathrm{APF}-458$ & 328 & $329+$ & 327 & 1 \\
\hline 36 & $S / A P F-473$ & 327 & $\mathbf{3 3 0}$ & 328 & 1 \\
\hline 37 & $S / A P F-482$ & 328 & 330 & 328 & 0 \\
\hline 38 & S/APF - 504 & $\mathbf{3 3 1}$ & 332 & 330 & -1 \\
\hline 38 & S/APF- 521 & 332 & 333 & 331 & -1 \\
\hline 40 & S/APF- 528 & 325 & 327 & 325 & 0 \\
\hline 41 & S/APF- 6 & 336 & rol) & 335 & -1 \\
\hline 43 & S/APF -489 & (Con & rol) 329 & 327 & -3 \\
\hline
\end{tabular}




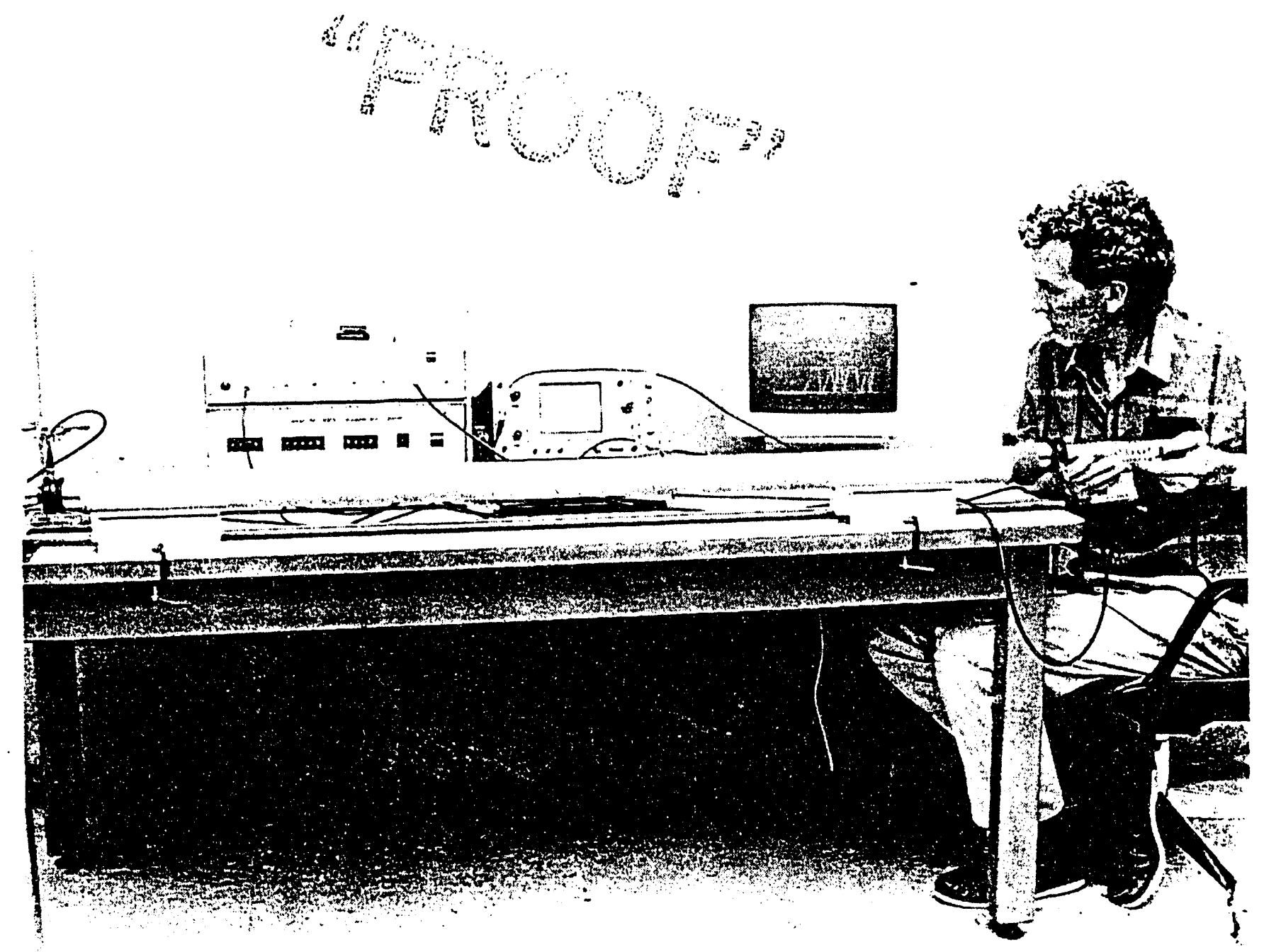

Figure B-1 - Ultran Time-Of-Flight Testing of 1.5 m Surveillance Candle Filters 


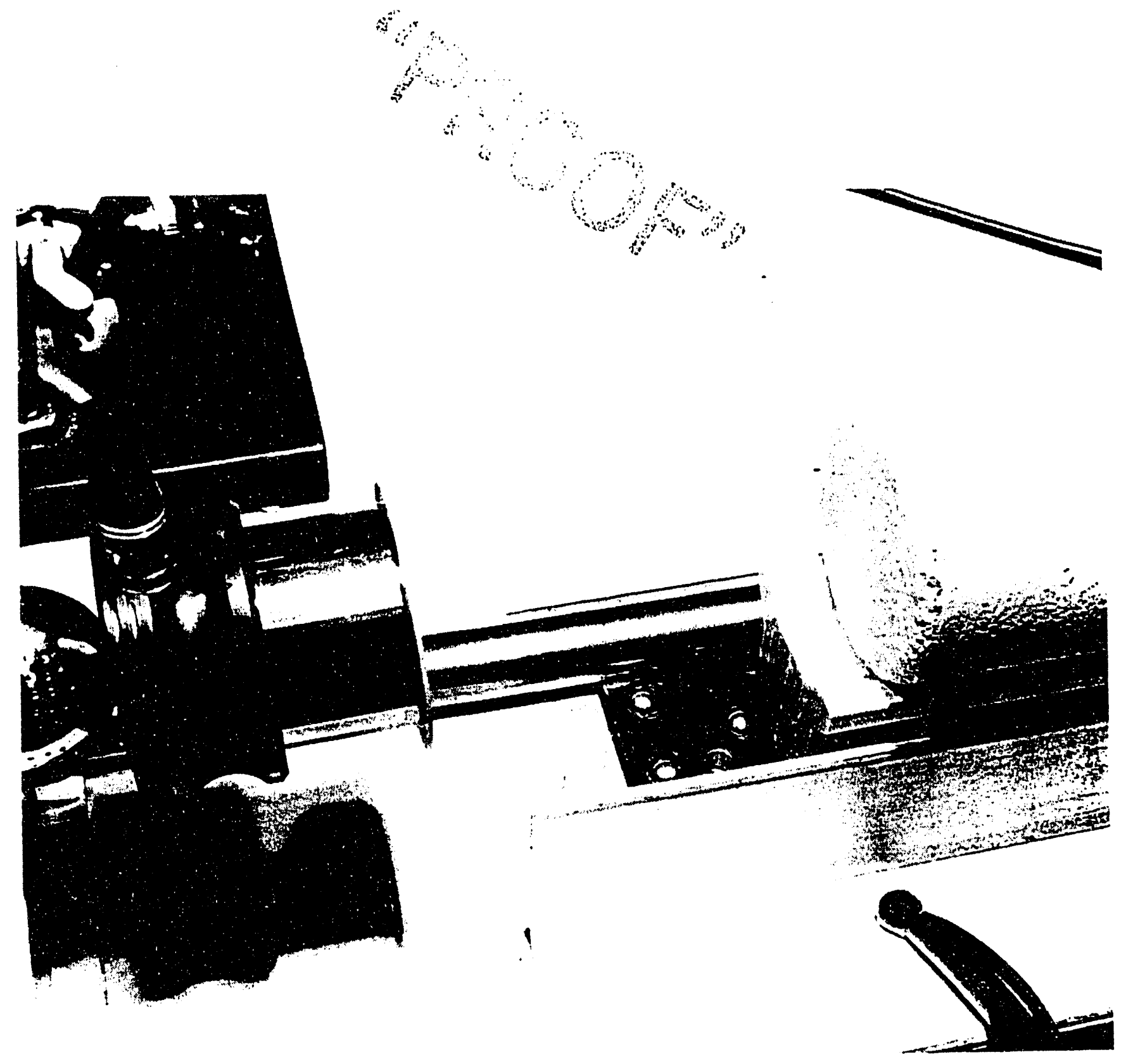

Figure B-2 - Configuration of Closed End Section of the Candle Filter Prior to Contact With the Urethane Membrane Covered Dry Couplant Transmitting Transducer 


\section{APPENDIX C}

THROUGH-THICKNESS TIME-OF-FLIGET MEASUREMENTS FOR SURVEILLANCE CANDLE FILTERS 
APPENDIX C

\section{THROUGH-THICKNESS TIME-OF-FLIGHT MEASUREMENTS \\ FOR SURVETLLANCE CANDLE FILTERS}

Failure of clay bonded silicon carbide candle filters has frequently been associated with material flaws that are generated during filter fabrication in the grain structure transition area of the Schumacher candle. Within in the first three to four inches from the top of the flange, the Schumacher candle consists of fine silicon carbide grains that are held together with an aluminosilicate clay binder. This dense area is generally not coated with an external membrane. Below the dense region is the remainder of the $1.5 \mathrm{~m}$ candle filter body which consists of coarse silicon carbide support grains. The coarse grains are also held together via the aluminosilicate clay binder phase. An external aluminosilicate fiber-silicon carbide grain membrane is applied to the candle body to prevent particle penetration into the support matrix. In an attempt to determine if fabrication flaws could be detected within the fine-to-coarse silicon carbide transition zone, through-thickness time-of-flight (TOF) measurements mere performed.

An Ultran BR-640A broad band receiver and BR-9400A burst pulser were used to determine the through thickness TOF measurement of six surveillance candle filters (Figure C-1). A 1.5 Mhz Ultran 143067 transmitting transducer with a delay line contoured to the candle O.D., and a 1.5 Whz Ultran 143068 receiving transducer with a delay line contoured to the candle I.D., were held in a spring loaded scissors-like fixture (Figure C-2). 
The fixture was placed at various locations along the candle wall below the flange with the transmitting transducer positioned along the candle 0.D., and the receiving transducer along the candle I.D. The spring deflection at contact with the candle body was adjusted to obtain a $12.1 \mu \mathrm{s}$ TOF delay. A Plexiglas cylindrical standard which had a TOF value of $13.1 \mu \mathrm{s}$ (including delay time) was used for calibration. A 100 Whz digitizing rate with a threshold of eight was used for data gate positioned between 0 and $20 \mu \mathrm{s}$. The collection accuracy of the unit was identified at $\pm 0.7 \mu \mathrm{s}$.

The six surveillance candles that were selected for the through-thickness TOF characterizations represent both low and high range full length TOF values that were reported in Appendix B. Candles which have significantly different TOFs (Schumacher's vs Westinghouse's data) were included. The resulting through-thickness TOF data for the six surveillance candles are presented in Table $\mathrm{C}-1$. Through-thickness data were generated at three locations within the fine grain structure at $\sim 3$ inches below the top of the flange, as well as within the coarse grain region at $\sim 4.5$ inches below the top of the flange.

The resulting through-thickness TOF values generated for the coarse region at $1.5 \mathrm{Khz}$ show good correlation with the full length TOF data. In particular, all $50 \mathrm{Khz}$ full length TOF values that were reported as high values in Appendix B, exhibit corresponding throughthickness values that exceed $5 \mu \mathrm{s} /$ in. Since a relatively small set of data was generated in this effort, final conclusions will not be made at this time with regard to the integrity of the fine-to-coarse grain transition section, nor to what effect that the fine-to-coarse grain transition area has on the overall TOF value generated for each candle filter. 

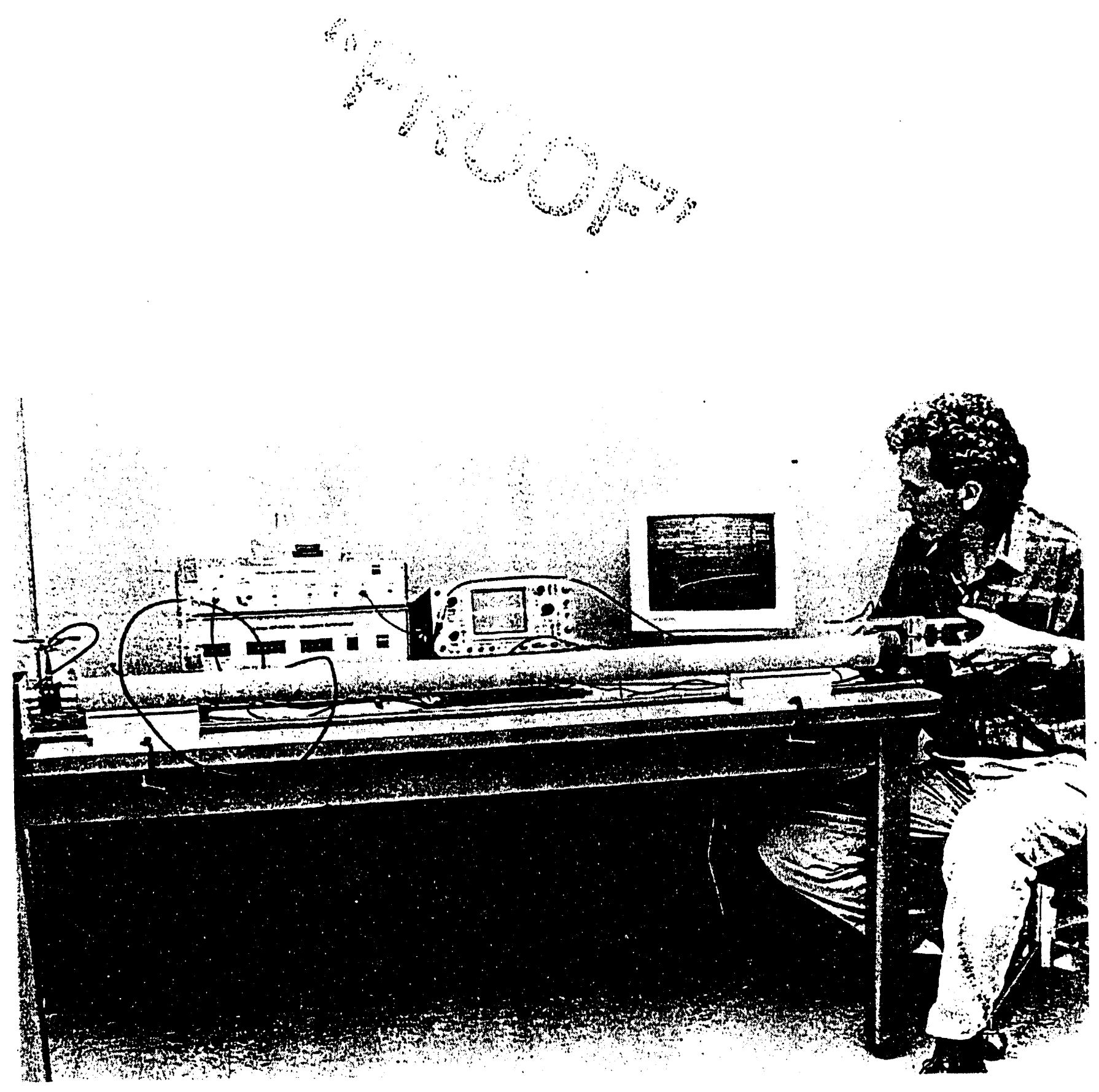

Figure C-1 - U1tran Time-0f-Flight Testing for Through-Thickness Measurement on 1.5 m Surveillance Candle Filters 


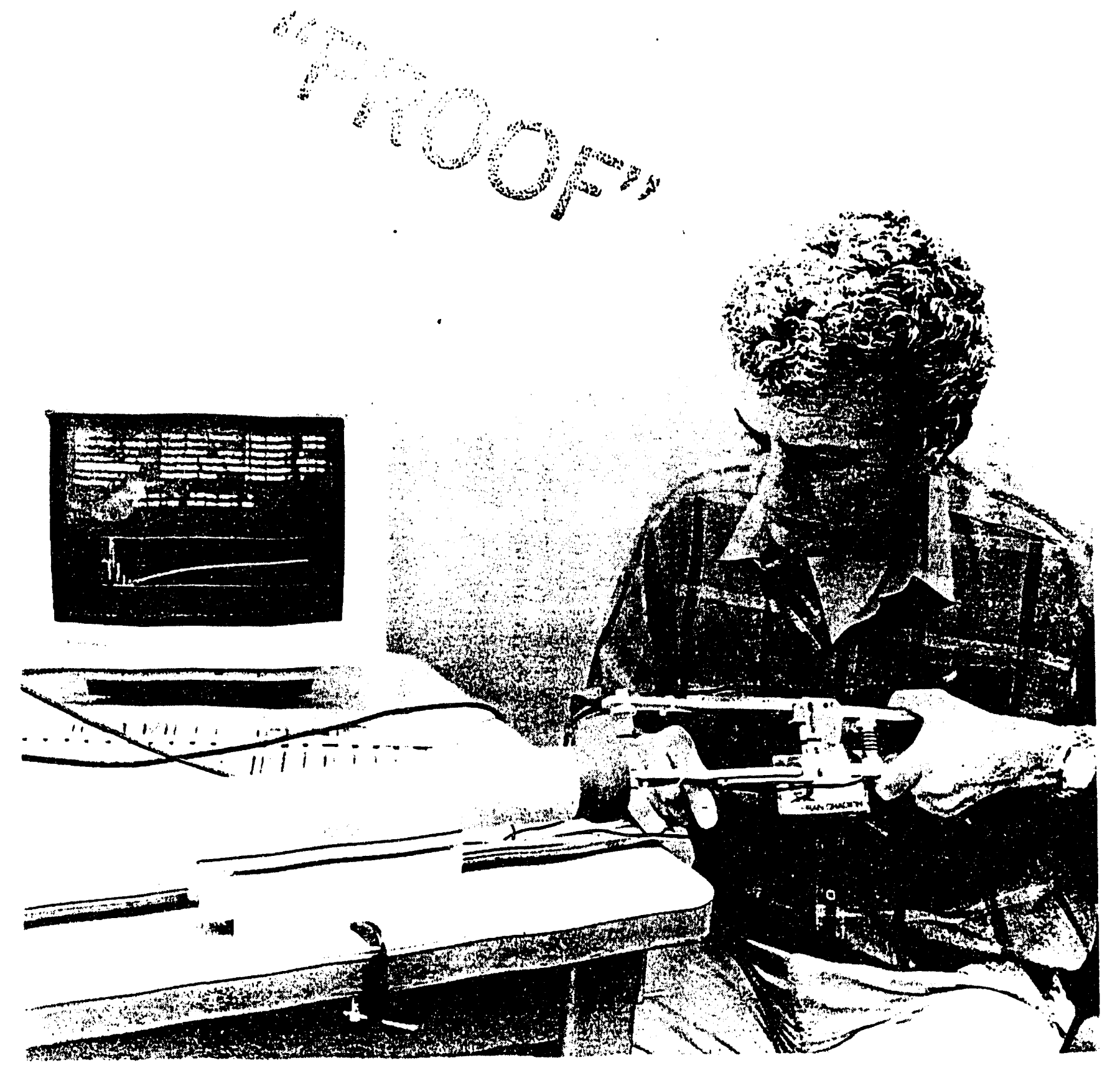

Figure C-2 - Through-Thickness TOF Transducer Fixture for Measurement along the Coarse-to-Fine Grain Transition Section of the Surveillance Candles 


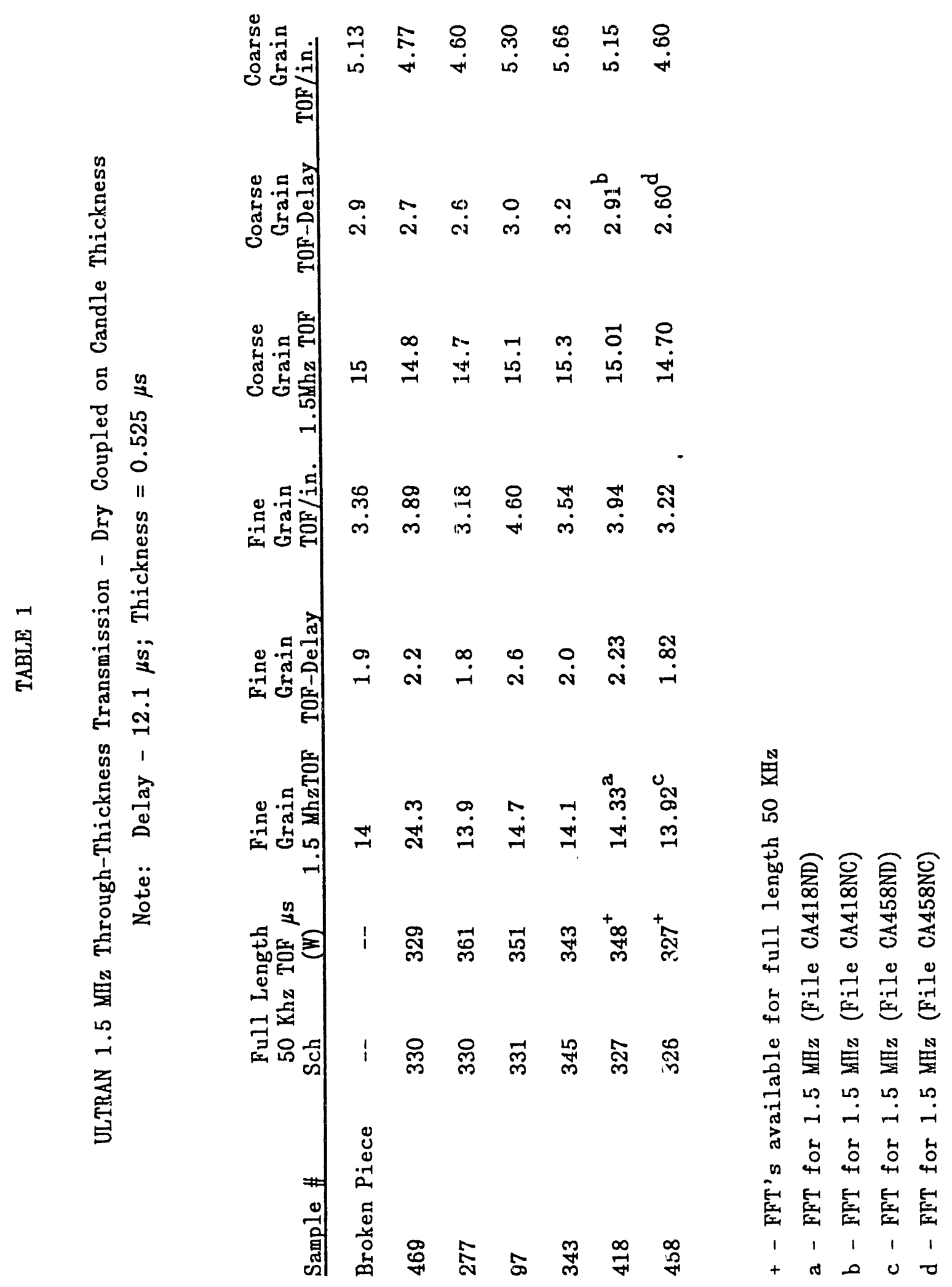



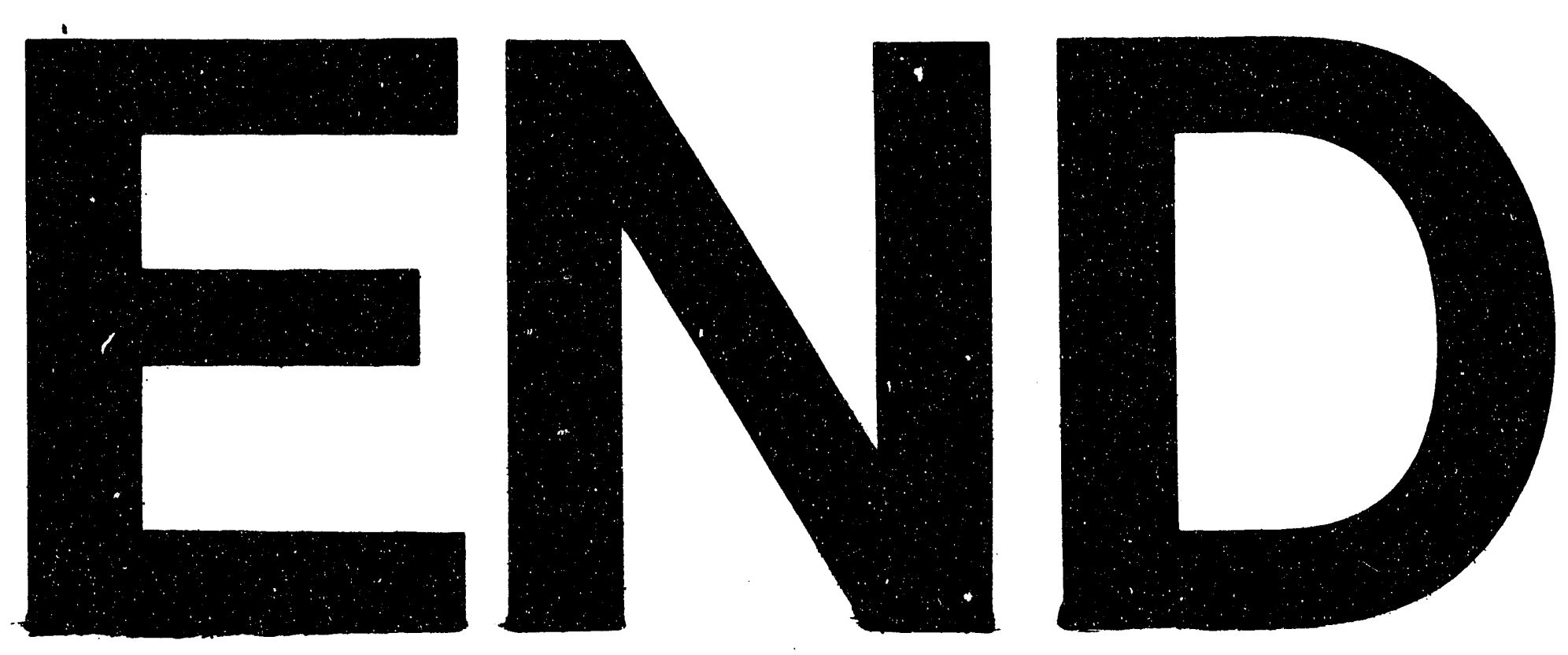

28

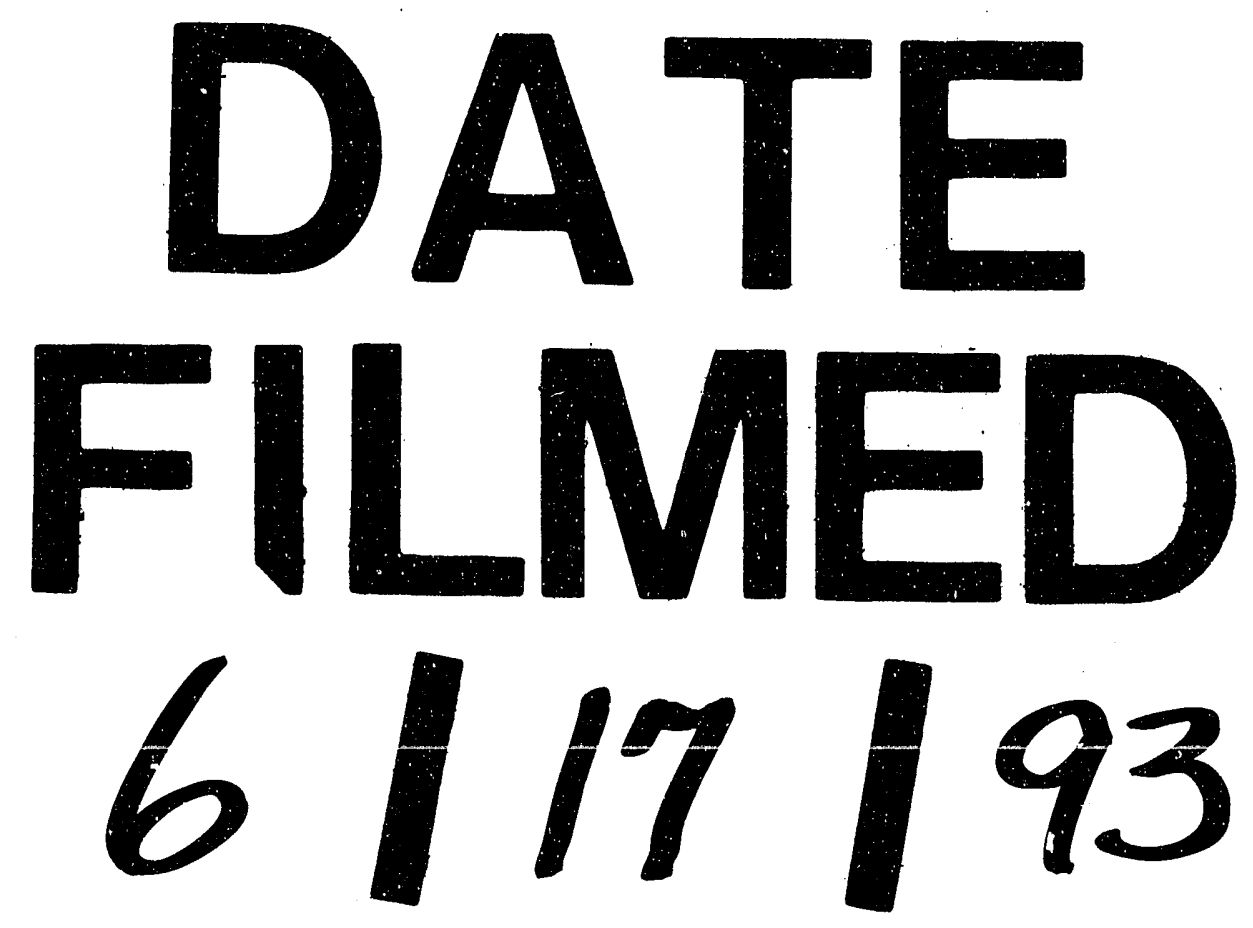


